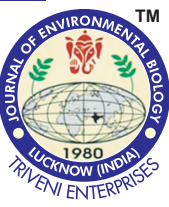

\title{
Laboratory assessment of GAC-packed IFAS for treatment of primary treated petrochemical wastewater
}

\section{Authors Info}

M.E. Ahmed*, A. Mydlarczyk and A. Abusam

Water Research Center, Kuwait Institute for Scientific Research, Safat, 13109, Kuwait

*Corresponding Author Email : miahmed@kisr.edu.kw

\section{Edited by}

Prof. Muhammad Aqeel Ashraf

\section{Reviewed by}

Dr. Onder Ayyildiz

Dr. Qusay F. Alsalhy

\begin{abstract}
Aim: In this study, the integrated fixed film activated sludge (IFAS) process was set up to include a high surface area growth support medium, which is granular activated carbon (GAC). This configuration was experimented to evaluate its ability to enhance the biodegradation process, utilizing both suspended growth and attached growth in a manner that can be optimized and aid in the removal of organics and nutrients, when GAC is used as a support material, in addition to providing increased capability to handle variable or shock loads.
\end{abstract}

Methodology: Batch laboratory-scale studies were conducted to assist in understanding the process behavior and aid in future piloting/upscaling at later phase.

Results: The process was found to be feasible with encouraging design parameters, such as its ability to reduce $C O D$, minimize the nutrients, and recover $D O$ levels in the effluent. More specifically, at high GAC loading case $\left(200 \mathrm{~g}-\mathrm{GACl}^{-1}\right)$, the attached biomass to suspended biomass ratio varied from 1 to 7 and for low GAC case $\left(100 \mathrm{~g}_{-} \mathrm{GAC}^{-1}\right)$, it varied from 0.5 to 5 over a 3 day period and then remained steady over 9 day experimental period. COD degradation rates of IFAS were mostly achieved during the first day of experiment where total biomass exceeded that of the control experiment without GAC, and during the consecutive days only slight improvement was noticed.

Interpretation: The integrated film activated sludge process was able to treat organic compounds in the petrochemical wastewater and also reduced nutrients represented by total nitrogen and total phosphorous and recovered DO levels. A high GAC loading case, the attached biomass to suspended biomass ratio varied from 1 to 7 and for low GAC case, it varied from 0.5 to 5 over a 3 day period and then remained steady over 9 day experimental period. Additionally, the COD degradation rates of IFAS were mostly achieved during the first day of experiment where total biomass exceeded that of the control experiment without GAC, and during the consecutive days only slight improvement was noticed.

Keywords: Granular activated carbon, Integrated fixed film activated sludge, Petrochemical wastewater, Wastewater treatment

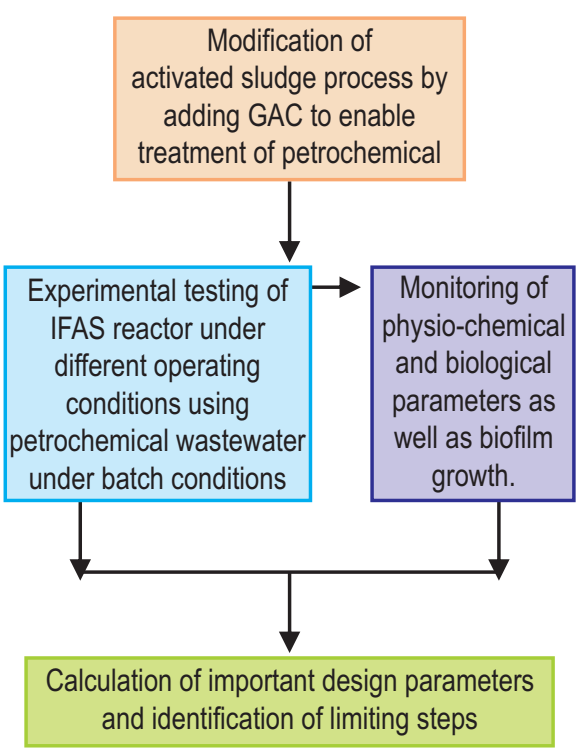

Citation: Ahmed, M.E., A. Mydlarczyk and A. Abusam: Laboratory assessment of GAC-packed IFAS for treatment of primary treated petrochemical wastewater. J. Environ. Biol., 40, 460-467 (2019). 


\section{Introduction}

Petrochemical and petroleum-based industrial wastewater treatment is a complex process, with demanding environmental management challenges, as by-products can be both volatile and toxic. Issues such as groundwater contamination; removal of aromatics, oil, grease, and organic compounds; and volatile organic compounds control have to be addressed in order to comply with environmental regulations and maintain a good customer image (Tiku, 2005). Therefore, it is imperative to invest in developing adaptive industrial wastewater treatment technologies to sustain water supply, healthier environments and industrial development (Shamsuddin et al., 2017). Common pollutants in petrochemical industry discharges are organics, particularly petroleum hydrocarbons (Biswas, 2018; Khan, 2018). Therefore, wastewater from petrochemical industries often require a combination of treatment methods to remove oil and other contaminants before discharge. In treating such waste waters, many processes have been used based on the variations of activated sludge with tertiary treatment. In addition to the variations in activated sludge process, physiochemical treatment processes are sometimes used (Chang et al., 2005; Rittman and McCarty, 2001; Randall and Sen, 1996; Coelho et al., 2006), and many other IFAS process combinations have also been proposed (Jianlong et al., 2000; Wang et al., 2004; Bai et al., 2015; Lin and Hsien, 2009; Ma et al., 2009; Khaing et al., 2010).

IFAS is composed of a solid packing material, on which the biofilm grows, with a void volume allowing a suspended growth process to contribute to the degradation process (Arshadullah et al., 2017; Kumruzzaman et al., 2017). The advantage of biofilm processes compared to activated sludge process(ASP) is that the anaerobic, anoxic and aerobic zones can be combined at a single stage. IFAS systems allow for the additional bacterial population to exist on a fixed surface, thereby eliminating the need to increase the suspended growth population (Brentwood, 2009). According to Brentwood (Brentwood, 2009), a group of researchers studied the IFAS process and proved that it has few advantages over the conventional, suspended growth-activated sludge process. This type of processesis capable of handling shock loads and can be easily used to retrofit the existing plants or as a stand-alone process for some industries.

According to Shamsuddin et al. (20017), a scholar demonstrated that as to compared with the free cell, the immobilized cell has several advantages, like it can increase the biodegradation rate through a higher cell loading, the bioprocess can be controlled more easily, the continuous process can take place at a high dilution rate without washout, and the catalytic stability of biocatalysts as well as tolerance against toxic compounds can be improved (Shamsuddin et al., 2017).
Additionally, enhanced nitrification and denitrification by using immobilized microbial cells have been reported by Arvidsson et al. (1998) and Garbayo et al. (2002).

In this study, the IFAS process was modified to include a high surface area growth support medium such as granular activated carbon (GAC). This configuration enhances the biodegradation process, utilizing both suspended growth and attached growth in a manner that can be optimized and aid in the removal of some trace contaminants by adsorption. In addition, it provides increased capability to handle variable or shock loads (Andreottola et al., 2003; Harvey et al., 2011).

In the light of above, batch laboratory-scale studies were conducted to assess and understand the process behavior and aid in future piloting/upscaling at later phase.

\section{Materials and Methods}

The petrochemical wastewater was collected from the first basin at Al-Wafra Industrial Wastewater Treatment Plant, which was primarily treated at the plant. The sample industrial wastewater was collected and utilized in laboratory reactors in all experiments.

The industrial wastewater was utilized at all four sets of experiments, i.e., at batch suspended growth only, batch adsorption on GAC only, batch attached growth on GAC and continuous flow attached growth on GAC. For the attached growth experiments, film thickness and detachment rates in the continuous flow experiments were characterized by microscopic examination. Initially, suspended growth experiments were planned to be conducted in well-stirred controlled containers for a period of 20 to 30 days; however, the observed degradation rates after the first day were more than $95 \%$ of the total degradation, and therefore subsequent experiments were conducted for 9 days only. The samples were collected daily.

The physio-chemical parameters analyzed were temperature, $\mathrm{pH}$, dissolved oxygen (DO), BOD, chemical oxygen demand (COD), total suspended solids (TSS), $\mathrm{NO}_{2}, \mathrm{NO}_{3}, \mathrm{NH}_{3}$, total nitrogen, total phosphorous and biomass represented by volatile suspended solids (VSS). All the parameters were analyzed following the standard procedure of APHA(2012).

Control samples, in addition to using laboratory-grade reagents and chemicals, were used to ensure results quality and Reliability. Statistical analyses was conducted to identify outliers and to estimate the means and averages, as well as standard deviations.

Adsorption experiments : Each experiment was conducted in well-stirred beakers (jar test apparatus) using a control volume. The experimental setup of each type of three experiments was similar to the jar test in which the known amount of GAC was put in jars or beakers with known amounts of wastewater. 
In the optimal GAC dose experiment, the GAC amount was varied $(50,100,150,200,250,300,400$, and $500 \mathrm{~g} \mathrm{GAC})$, and the wastewater amount was held constant at $1 \mathrm{I}$ and ample time (1d) was allowed for equilibrium.

In the adsorption kinetics experiment, the optimal dose of GAC (determined from the previous the experiment to be $200 \mathrm{~g}$ of $\mathrm{GAC}$ ) was mixed with the wastewater sample, and the sample was analyzed in 15, 30,60, 90, 120, 180 min time intervals.

The adsorption isotherms were determined using the optimal GAC dose (200 g of GAC) while changing the initial wastewater sample concentration and analyzing after equilibrium ( $1 \mathrm{~d}$ was allowed for equilibrium). Experiments were conducted in completely mixed 1 I well stirred beakers.

Fitting of adsorption isotherms was carried out using equations 1 to 3 .

$\begin{array}{ll}\text { Linear } & q=K C f \\ \text { Freundlich } & q=K C_{f}^{1 / n} \\ \text { Langmuir } & q=\frac{a K C_{f}}{1+a C f}\end{array}$

Where, $q$ is the sorbed mass per unit weight of adsorbent, $C_{f}$ is the final equilibrium solution concentration, and $K$ is the adsorption capacity and $a$ is the Langmuir adsorption constant (Metcalf and Eddy, 2014).

Batch suspended growth experiments: In the batch suspended growth experiments, bacterial cultures were acquired from the Al-Wafra industrial wastewater treatment plant, and the industrial wastewater samples were then mixed with cultures in one vessel ( $1 \mathrm{I}$ beakers). All the parameters were monitored daily. The beakers were stirred using a jar-test apparatus.

Batch attached growth experiments: In the batch attached growth on GAC experiments, the cultures were allowed to grow on the GAC, and the biological film coverage and homogeneity were observed by microscopic examination. Then, the sample industrial wastewater was added to the $200 \mathrm{~g}$ of GAC in 1 । beakers. All the parameters were monitored daily for each beaker including the control flask.

Attached biomass determination: Batch attached growth on GAC experiments (low and high GAC amounts) were conducted and the amount of attached biomass was determined. GAC in each beaker was rinsed with distilled water, and ground in known amounts of distilled water. Then standard procedures for VSS determination (APHA, 2012) was followed (Lu et al., 2013).

\section{Results and Discussion}

An initial sampling from Al-Wafra industrial wastewater treatment plant revealed that petrochemical wastewater $\mathrm{BOD}$, COD, TN, and TP vary between 693 to 505,1190 to 912,60 to 79 , 15 to $8 \mathrm{mg} \mathrm{l}^{-1}$ respectively before and after the primary treatment stage. This research tested the integrated biological film process for the secondary treatment of petrochemical wastewater, therefore, primarily treated wastewater was used. It is important to note that these concentrations vary greatly in each sample and, therefore, the actual used concentrations were reported in each experiment.

Petrochemical industrial wastewater behavior in granular activated carbon: The main concern in this research was the organic compounds represented by $\mathrm{COD}$ and BOD, and the nutrients represented by total nitrogen and total phosphorous. The following results were predominantly focused on these two aspects. Three experiments were conducted to determine the optimal GAC dose, to infer upon adsorption kinetics and to determine adsorption isotherms. The results are described in the following sections.

Optimal granular activated carbon amount: To determine the optimal GAC amount to be used in a given volume of wastewater, a design experiment was conducted. The experiment (Fig. 1) revealed that the adsorbed amount decreased sharply as GAC amount increased between 150 and $200 \mathrm{~g}$, and then as the GAC amount increased, further increase in the adsorbed amount is minute (Ademiluyi et al., 2009). Therefore, $200 \mathrm{~g}$ of GAC was used for each 1 I wastewater.

Adsorption kinetics: This experiment was carried out to understand the behavior of contaminants' adsorption in time and to determine the limiting factors to reach equilibrium, if any. Fig. 2 shows that the equilibrium was reached in less than half an hour at the most and that the kinetic process is exponential as confirmed by many researchers (Echenfelder, 1999; LaGregaet al., 2010). This means the adsorption process kinetics is not the limiting step in the IFAS process and that the contaminants are adsorbed, almost, instantaneously.

Adsorption isotherms: The adsorption isotherms give the final concentration of the wastewater when a known amount of GAC is added if the initial concentration is known. This process has been described mathematically by many empirical formulae (Metcalf and Eddy, 2014). Fig. 3 presents the results of the adsorption isotherms using $200 \mathrm{~g}$ of GAC in 1 I of primary treated petrochemical wastewater.

It is worth mentioning that the four parameters shown in Fig. 3 are lump sum parameters that are not frequently used in adsorption experiments. However, they were used here in the adsorption isotherms to identify limitations of the process as related to biofilm activity within the pores of GAC and to identify the role of adsorption on the process startup in future flow through runs (Dorado et al., 2012). Table 1 shows the results of fitting the 


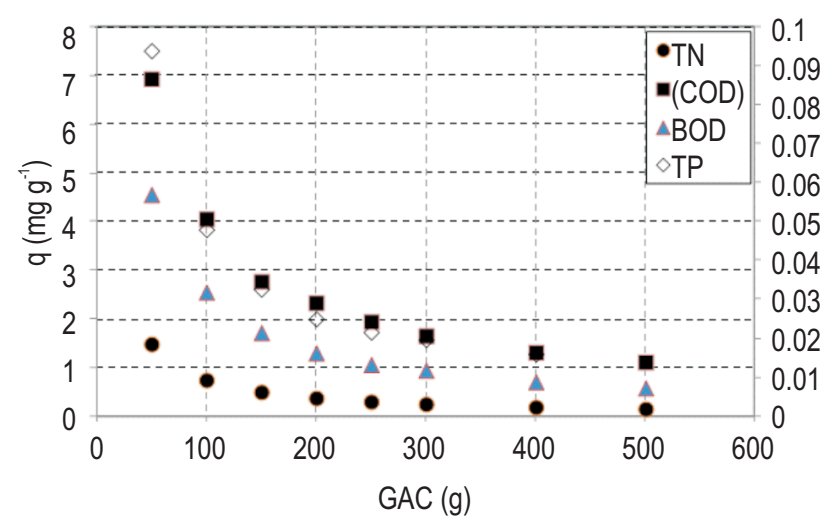

Fig. 1: Amount of biochemical oxygen demand (BOD), chemical oxygen demand (COD), total nitrogen (TN), total phosphorous (TP), adsorbed versus $G A C$ amount used.

TN
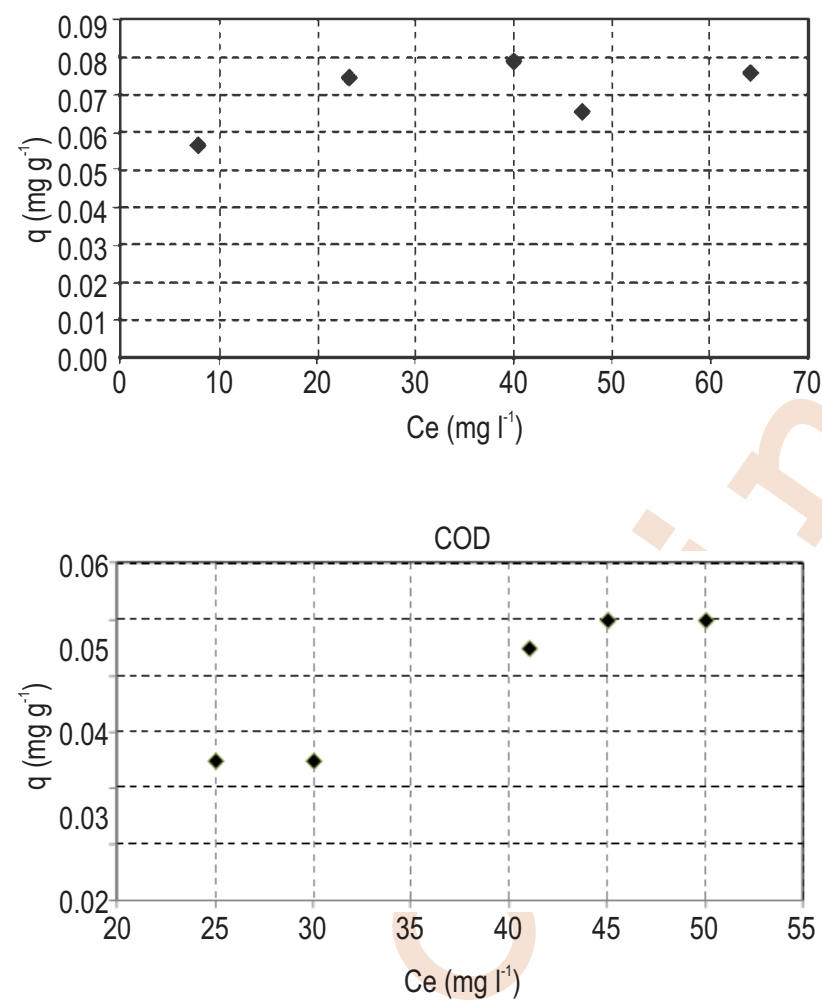

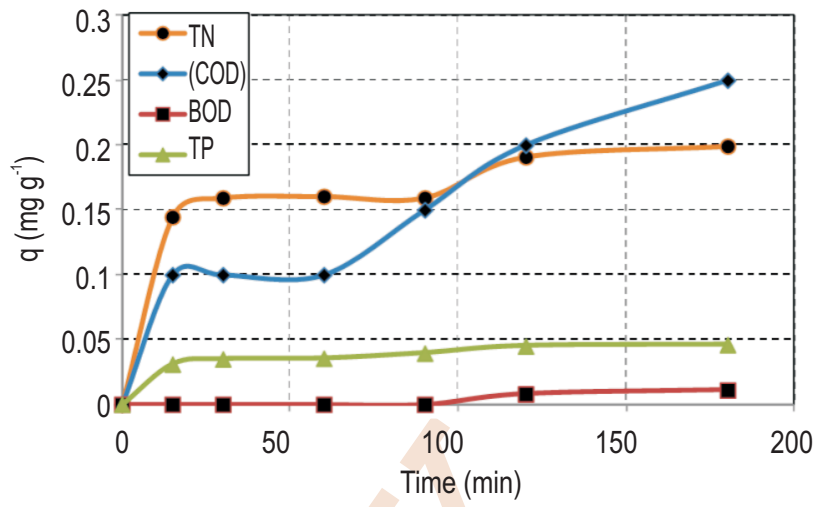

Fig. 2 : Amount of biochemical oxygen demand (BOD), chemical oxygen demand (COD), total nitrogen (TN), total phosphorous (TP), adsorbed on GAC versus time.
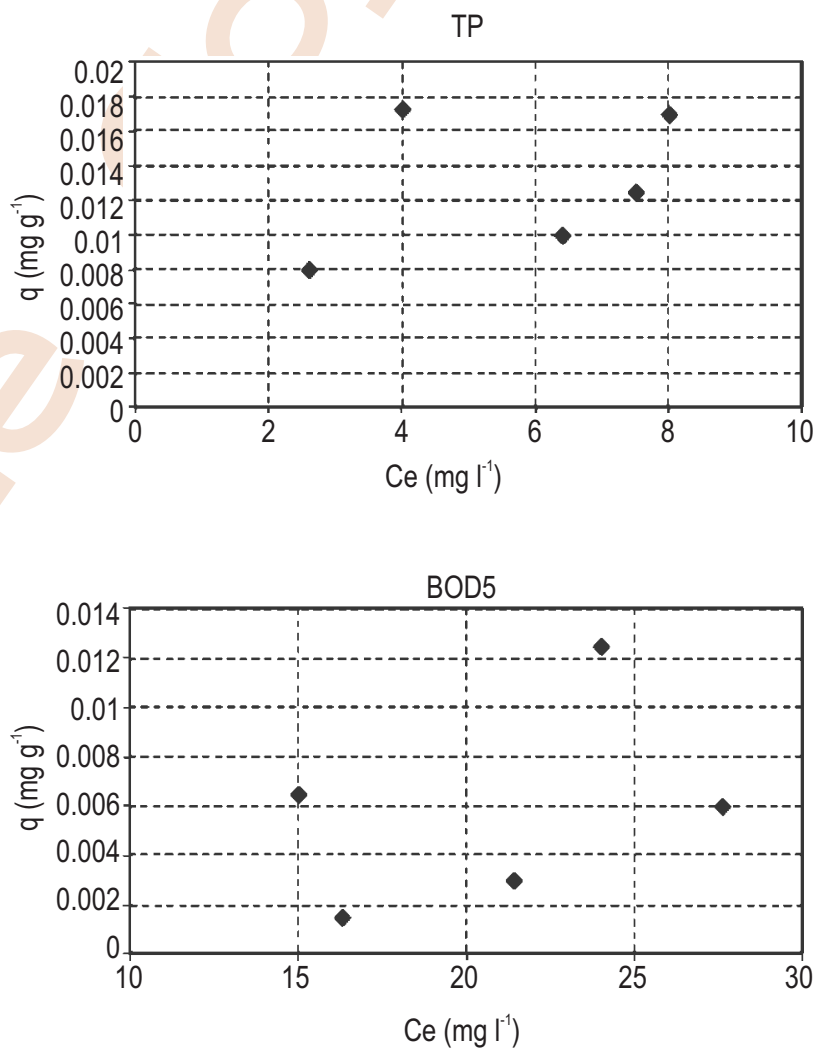

Fig. 3 : GAC adsorption isotherms for petrochemical wastewater. Biochemical oxygen demand (BOD), chemical oxygen demand (COD), total nitrogen (TN), total phosphorous (TP).

adsorption isotherms to the most known three adsorption isotherms shown in eq. 1 to 3 subsequently.

As seen in Table 1, the R-square values for Langmuir isotherms was higher than those for linear and Freundlich isotherms for total nitrogen and total phosphorous while for COD, aBOD R-square values were similar.
For total nitrogen and total phosphorous, the best fit is the Langmuir isotherm which assumes monolayer coverage (LaGrega et al., 2010) although both fits were not very good, and can be attributed to the lump sum nature of contaminants and high concentrations of petrochemical wastewater. Obviously, BOD did not describe the partitioning (adsorption) of organics onto the GAC very well. However, the superiority of COD fit to 
Table 1: R-square values for fitting Linear, Freundlich and Langmuir Isotherms to adsorption data

\begin{tabular}{lcll}
\hline Parameter & Linear isotherm & Freundlich isotherm & Langmuir isotherm \\
\hline Total nitrogen & 0.3507 & 0.553 & 0.7097 \\
Total phosphorous & 0.14 & 0.2357 & 0.3766 \\
Chemical oxygen demand & 0.9318 & 0.9259 & 0.9066 \\
Biochemical oxygen demand & 0.1667 & 0.1943 & 0.191 \\
\hline
\end{tabular}

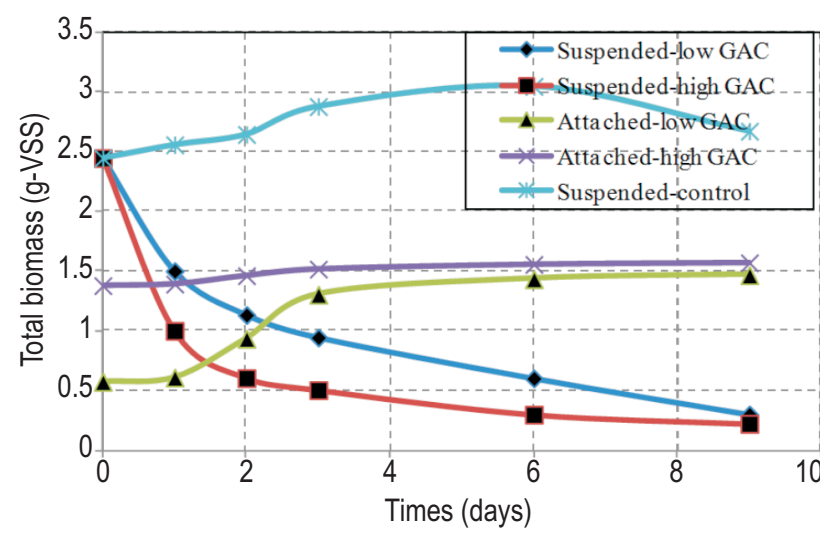

Fig. 4 : Biomass amount in attached and suspended growth for high and low GAC cases.

three adsorption isotherms was surprising although the best fit was linear isotherm. Therefore, COD was used as the main substrate parameter with a linear partitioning coefficient of 0.0012 which indicates low partitioning onto the solid phase and pose a bioavailability limitation.

The adsorption experiments suggest that adsorption plays a role during the initial phase of attached growth experiment and this role is positive with respect to priming the reactor and reaching steady state (Dorado et al., 2012). On the other hand, there is an impact of using GAC as a support medium that could be more pronounced in the nutrient's removal. As nutrients are consumed during the process, desorption may occur.

Priming experimental reactor and biomass growth: The biomass growth was investigated using primary treated wastewater from the secondary activated sludge units of AI-Wafra Industrial Wastewater Treatment Plant of the characteristics described in Section 3. Air was supplied using air compressor (model Condor MDR2/11 bars from PEAK SCIENTIFIC Company) to maintain DO levels between 2 to $4 \mathrm{mg} \mathrm{I}^{-1}$ in 20 I wastewater containers. VSS in the wastewater and GAC phases was monitored with time for 9 days. The results are shown in Fig. 4.

As seen in Fig. 4, the suspended growth phase VSS increased with time in the suspended phase only (control sample) to reach $4.5 \mathrm{gl}^{-1}$. When GAC was introduced at low amount $\left(100 \mathrm{~g} \mathrm{l}^{-1}\right)$,

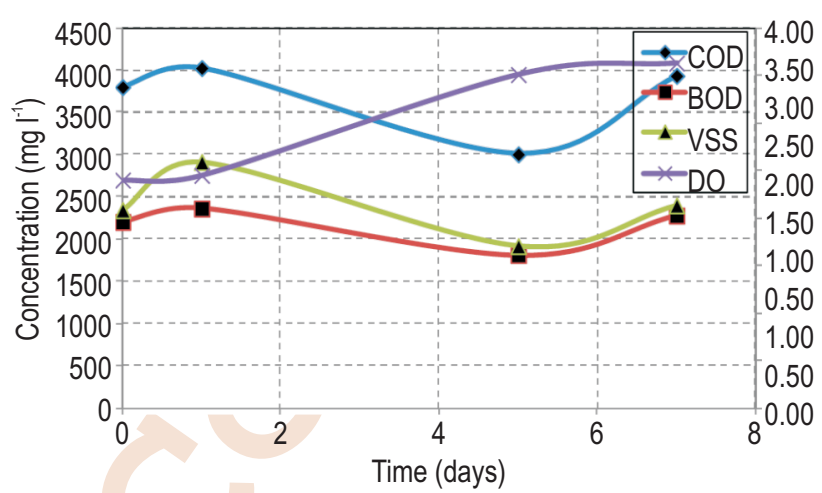

Fig.5: Biochemical oxygen demand (BOD), Chemical oxygen demand (COD), Dissolved oxygen (DO) and Volatile suspended solids (VSS) concentrations during batch suspended growth treatment of petrochemical wastewater.

the suspended phase VSS droped to minimum values while the attached phase biomass increased to reach its highest in 3 days. At higher GAC doses $\left(200 \mathrm{gl}^{-1}\right)$, the same phenomena were observed, except that steady state biomass was achieved in 2 days. The corresponding biomass ratios varied between 0.5 to 5 times attached versus suspended biomass over 9 day duration of the experiments for low GAC case, and between 1 to 7 for high GAC case. Similar values were earlier reported by Wang and Wu (2004) and Yu et al. (2001). An important observation is that, apparently, the total biomass exceeds the control biomass only during the first day of experiment in high GAC case. This suggests, depending on further experiments, to a fully GAC loaded design upon real life application. On the other hand, the suspended biomass in the control experiments decreased after six days of operation suggesting improved performance of the attached growth process on longer periods of operation. Additionally, the transformation of suspended biomass, in itself, is a benefit as washed microorganisms are reduced compared to suspended growth process such as activated sludge.

In summary, GAC enhanced the biomass greatly and reached its highest values in 2-3 days, inthe present study. This conclusion is the basis for testing biodegradation in the following experiments.

Batch suspended growth: The main goal of this experiment was to evaluate the ability of indigenous biological cultures to degrade petrochemical wastewater and to estimate the biodegradation 


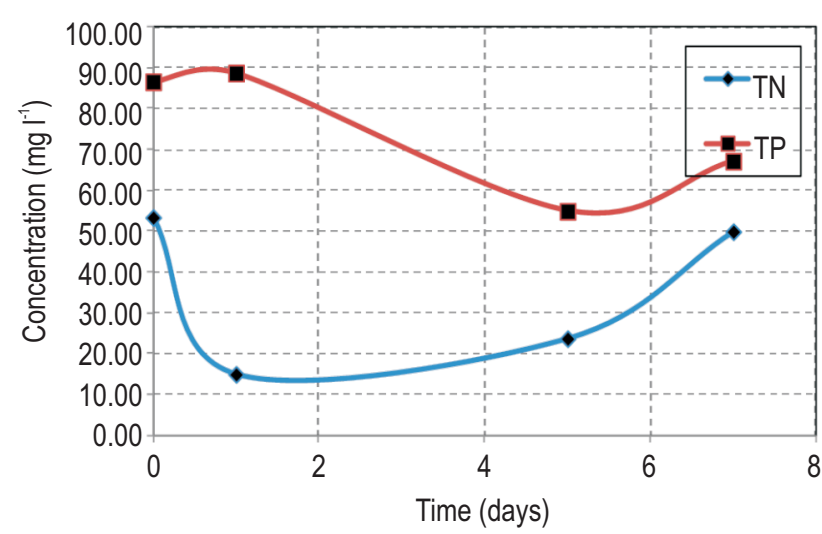

Fig.6: Total nitrogen (TN) and total phosphorous (TP) concentrations during batch suspended growth treatment of petrochemical wastewater.

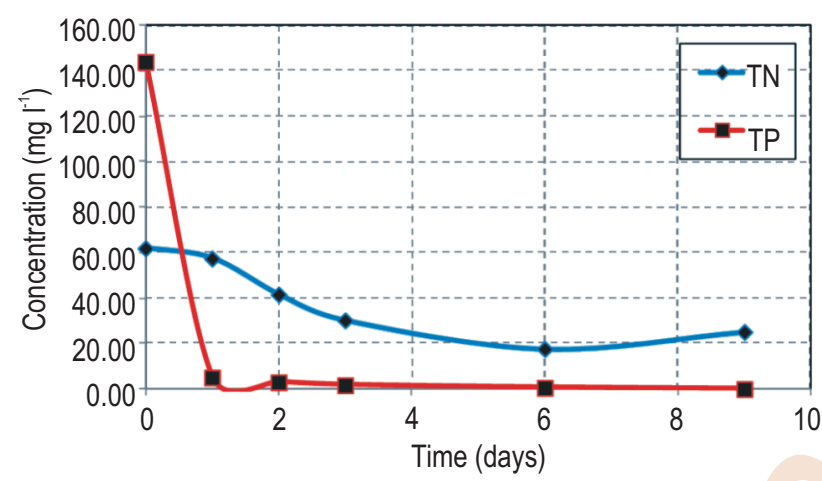

Fig. 8 : Total nitrogen (TN) and total phosphorous (TP) concentrations during batch attached growth treatment of petrochemical wastewater (low GAC).

parameters or Monod kinetic parameters (Metcalf and Eddy, 2014). The results of the batch suspended growth experiments are shown in Fig. 5 for BOD and COD and in Fig. 6 for total phosphorous and total nitrogen, respectively.

Both BOD and COD reached minimum concentrations in 5 days (Fig. 5), and after that the death of microorganisms raised the BOD and COD concentrations. Seemingly, this is congruent with the nutrients (Fig. 5), where they are consumed in parallel rates until day 5 . VSS followed the BOD and COD concentrations as they are their primary substrate. An important quality indicator is $\mathrm{DO}$, which increased from 2.5 to $3.5 \mathrm{mg} \mathrm{l}^{-1}$ after the experiment.

In an earlier study (Ahmed et al., 2017), fitting to Monod reaction kinetic equation was conducted to estimate the biodegradation parameters. The fitting resulted in a yield coefficient of 4.59 per day and a decay coefficient of 1.61 per day indicating reasonable activity of the microorganisms, but also a high decay rate that can be attributed to toxicity of wastewater and the limitations posed by nutrients and substrate concentrations

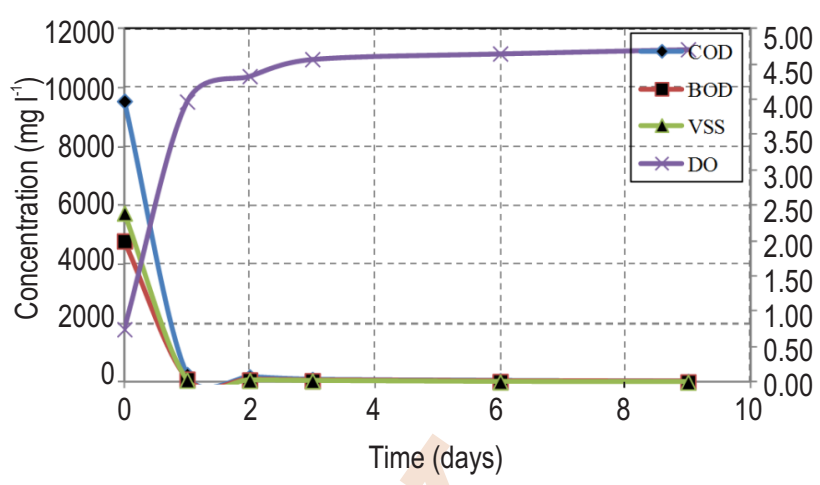

Fig. 7: Biochemical oxygen demand (BOD), Chemical oxygen demand (COD), Dissolved oxygen (DO) and Volatile Suspended Solids (VSS) concentrations during batch attached growth treatment of petrochemical wastewater (low GAC).

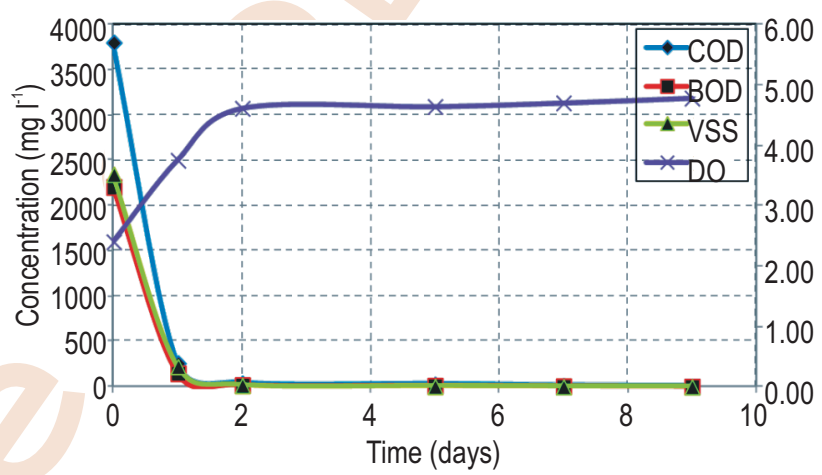

Fig. 9 : Biochemical oxygen demand (BOD), Chemical oxygen demand (COD), Dissolved oxygen (DO) and Volatile Suspended Solids (VSS) concentrations during batch attached growth treatment of petrochemical wastewater (high GAC).

\section{(Metcalf and Eddy, 2014) is shown in Fig. 6.}

Fig. 6 shows an overall reduction of TP and TN with and initial decrease in both TP and TN, and slightly increased after day 5 .

The role of attached and suspended biomass in the nitrification denitrification processes has been investigated by a scholar (Wang and Wu, 2004). No significant difference was observed between the role two biomass in the nitrification denitrification processes, however, the attached biomass had a stronger ability to resist the nitrification inhibitor (Wang and Wu, 2004). Similar observations were noted in the present study, but the point to be noted is that the suspended and attached biomass were nearly equal in the study of wang and $\mathrm{Wn}$ (2004), however, in this the ratio had reached 14 .

Batch attached growth experiments were carried out to evaluate the effects of adding the support media (GAC) to enhance degradation rates and were conducted at varying 


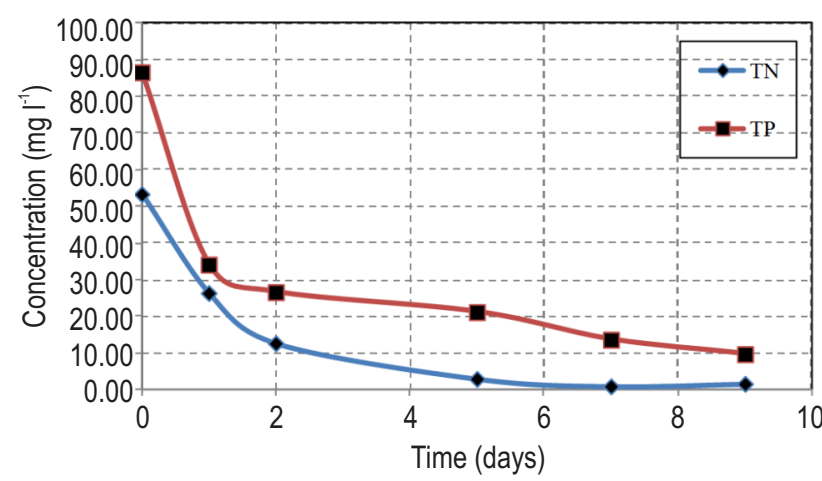

Fig. 10 : Total nitrogen (TN) and total phosphorous (TP) concentrations during batch attached growth treatment of petrochemical wastewater (high GAC).

amount of GAC added (high = $200 \mathrm{~g}$ and low $=100 \mathrm{~g}$ ). Figs. 7 and 8 show the results of low GAC experiments and Figs. 9 and 10 show the results of high GAC experiments.

By comparing the results in Fig. 5 with the results in Figs. 7 and 9 , the superiority of adding support media can be seen clearly. In addition, the concentrations of DO were higher in the attached growth case (above $4.5 \mathrm{mg} \mathrm{l}^{-1}$ ) than those in the suspended growth experiment $\left(3.5 \mathrm{mg} \mathrm{l}^{-1}\right)$.

Microorganisms in the liquid phase, as well as TN and TP, were reduced greatly in the attached growth experiments. It was also observed that high GAC was more efficient in removing organic compounds, as well as TP and TN. Although this also relates also to the biological activity, it is obvious that the adsorption process may have a contribution.

Fig. 4 demonstrates that at steady state, the attached biomass increased 7 times that in the suspended in the liquid phase. During first day most of the degradation took place and the rate of degradation of attached biomass can be safely assumed to be higher than the rate of degradation of suspended biomass.

Confinement of biomass increasingly to the GAC phase does not lead to ignoring the contribution of suspended cells to substrate removal (Chang et al., 2005). The suspended rate of degradation can still range between 14 and $20 \%$ of the overall substrate degradation rate. Similar results have been reported by Yu etal. (2004) where suspended bacteria were reported to be less than $1 \%$ of the biomass in a biofilm reactor, yet it transformed up to $30 \%$ of the substrate (toluene).

In summary, the integrated film activated sludge process was found to be feasible and promising for testing at a pilot-scale level. Improvements at pilot scale can be improved by improving the size of the reactor, supplying co-substrates, and adjusting the hydraulic and organic loading. These improvements can be assisted by developing a mathematical model.
The study concludes that the treatment of petrochemical wastewater, using an integrated fixed film process, is viable despite limitations posed by the toxicity of petrochemical wastewater, limited substrate and nutrients, and low sorption or partitioning onto the solid phase. Most important is that the biofilm development is greatly enhanced by immobilization on the high surface area GAC.

The importance of this research is its addition to few attempts to enhance treatment of petrochemical wastewater using real wastewater samples from an existing industrial wastewater treatment plant.

\section{Acknowledgment}

The authors would like to thank the Kuwait Institute for Scientific Research (KISR) for funding the study (project no. WT040K).

\section{References}

Ademiluyi, F.T., S.A. Amadi and O.J. Nimishingha: Adsorption and treatment of organic contaminants using activated carbon from waste Nigerian bamboo. J. App. Sci. Environ. Manag., 13, 39-47 (2009).

Ahmed, M., A. Mydlarczyk and A. Abusam: Kinetic modeling of GAC IFAS chemostat for petrochemical wastewater treatment. J. Water Resour. Hydraulic Engin., 6, 27-33 (2017).

Andreottola, G., P. Foladori, G. Gatti, P. Nardelli, M. Pettena and M. Ragazzi: Upgrading of a small overloaded activated sludge plant using a MBBR system. J. Environ. Sc. Hlth., Part A: Toxic Haz. Subs. Environ. Engin., 38, 2317-28 (2003).

APHA: Standard methods for examination of water and wastewater. American Public Health Association, Washington, D.C., USA (2012).

Arshadullah, M., M. Suhaib, R. Baber, M. Usama, B. Uz-Zaman, I.A. Mahmood and S.I. Hyder: Growth of Chenopodium quiona Wild under naturally salt affected soils. Malays. J. Sustain. Agric., 1, 0103 (2017).

Arvidsson, P., K. Nilsson, H. Hakanson and B. Mattison: Monitoring nitric oxide from immobilized denitrifying bacteria, Pseudomonas stutzeri, by the use of chemiluminescence. Appl. Microbiol. Biotechnol., 49, 677-681(1998).

Bai, Y., X. Quan, Y. Zhang and S. Chen: Enhancing nitrogen and phosphorus removal in the BUCT-IFAS process by bypass flow strategy. Water Sci. Technol., 72, 528-533 (2015).

Biswas, J.K.: A few words on black rice. Malays. J. Halal Res.,1, 01-02 (2018).

BRENTWOOD: Integrated Fixed Film Activated Sludge (IFAS) Technology. Reading: Brentwood Industries, Inc. (2009).

Chang, H.T., S.J. Parulekar and M. Ahmed: A dual-growth kinetic model for biological wastewater reactors. Biotechnol. Progr., 21, 423-31 (2005).

Coelho, A., V.A. Castro, M. Dezotti and G.L. Santa'Anna Jr.: Treatment of petroleum refinery wastewater by advanced oxidation processes. J. Hazard. Mater., B137,178-84 (2006).

Dorado, A.D., J. Lafuente, D. Gabriel and X. Gamisans: Interaction between sorption and biodegradation in a biofilter packed with 
activated carbon. Water Sci. Technol., 66,1743-1750 (2012).

Echenfelder, W.W.: Industrial Water Pollution Control. $3^{\text {td }}$ Edn., NY, McGraw-Hill (1999).

Garbayo, I., R. Leon, J. Vigara and C. Vilchez: Inhibition of nitrate consumption by nitrite in entrapped Chlamydomonas reinhardtti cells. Biores. Technol., 81, 207-215 (2002).

Harvey, G., H. Hasibul, D. Dipesh, M. Charles and H. Yung-Tse: Biofilm fixed film systems. Water, 3, 843-868 (2011).

Jianlong, W., S. Hanchang and Q. Yi: Wastewater treatment in a hybrid biological reactor (HBR): Effect of organic loading rates. Process Biochem., 36, 297-303 (2000)

Khaing, T.H., J., Y. Li, N. Wai and F.S. Wong: Feasibility study on petrochemical wastewater treatment and reuse using a nove submerged membrane distillation bioreactor. Sep. Purif. Technol., 74, 138-143 (2010).

Khan, M.M.H.: Occurrence, distribution, host preference and damage severity of Red pumpkin beetle -A review. Malays. J. Halal Res., 1 03-09 (2018).

Kumruzzaman, M. and A. Sarker: Water requirements for various crops and impact of irrigation in barind area. Malays. J. Sustain. Agric.,1 04-07 (2017).

LaGrega, M., P. Buckingham and J. Evans: Hazardous waste management. Waveland Pr Inc; Reissue Edition (2010).

Lin, Y. and T. Hsien: Kinetics of biodegradation of phenolic wastewater in a biofilm reactor. Water Sci. Technol., 59, 1703-1710 (2009).

Lu, M., L. Gu and W. Xu: Treatment of petroleum refinery wastewater using a sequential anaerobic-aerobic moving-bed biofilm reactor system based on suspended ceramsite. Water Sci. Technol., 67, 1976-1983 (2013).
Ma, F., J.B. Guo, L.J. Zhao, C.C. Chang D. Cui: Application of bio augmentation to improve the activated sludge system into the contact oxidation system treating petrochemical wastewater. Biores. Technol., 100, 597-602 (2009).

Metcalf and Eddy: Wastewater Engineering: Treatment and Resource Recovery. NY. McGraw-Hill (2014).

Randall, C.W. and D. Sen: Full-scale evaluation of an integrated fixedfilm activated sludge (IFAS) process for enhanced nitrogen removal. Water Sci. Technol., 33, 155-162 (1996).

Rittman, B. and P. McCarty: Environmental Biotechnology: Principles and Applications. New York: McGraw-Hill Science Engineering (2001)

Shamsudin, S.B. and A.M. Arshad: Association of blood lead levels and working memory ability of primary school children surrounding excopper mining area in Ranau, Sabah (Malaysia). Acta Sci. Malays., 1, 01-03 (2017).

Shamsudin, S.B., A. Marzuki, M.S. Jeffree and K.A. Lukman: Blood lead concentration and working memory ability on Malay Primary school children in urban and rural area, Malacca. Acta Sci. Malays., 1, 04-07 (2017).

Tiku, S.: Wastewater management in the petrochemicals industry. Water World, 5, 7-10 (2005)

Wang, J.L. and L.B. Wu: Wastewater treatment in a hybrid biological reactor (HBR): nitrification characteristics. Biomed. Environ. Sci., 17, 373-379 (2004).

Yu, H., B.J. Kim and B.E. Rittmann: Contributions of biofilm versus suspended bacteria in an aerobic circulating-bed biofilm reactor. Water Sci. Technol., 43, 303-310 (2001). 